\title{
Josephus's Paraphrase Style and the Testimonium Flavianum
}

\author{
Gary J. Goldberg* | ORCID: oooo-0oo1-5590-3176 \\ Independent scholar, Campbell, CA, USA \\ GJGoldberg@earthlink.net
}

\begin{abstract}
The controversial account of Jesus in Josephus's Jewish Antiquities 18.63-64, known as the Testimonium Flavianum, has puzzling similarities to Luke 24.18-24, a portion of the Emmaus narrative. This article proposes an explanation based on established research into Josephus's methods of composition. Through a phrase-by-phrase study, this article finds that the Testimonium can be derived from the Emmaus narrative using transformations Josephus is demonstrated to have employed in paraphrasing known sources for the Antiquities. Precedents are identified in word adoption/ substitution and content modification. Consequently, I submit that the Testimonium is Josephus's paraphrase of a Christian source. This result also resolves the difficulties that have raised doubts about the Testimonium's authenticity, with implications for the understanding of the historical Jesus.
\end{abstract}

\section{Keywords}

Josephus - Testimonium Flavianum - Luke - Emmaus - paraphrase

\section{Introduction: the Paraphrase Model}

The description of Jesus in Josephus's Jewish Antiquities 18.63-64, a passage known as the Testimonium Flavianum, a curious series of resemblances with Lk. 24.18-27, a portion of the Emmaus narrative, as I have pointed out in a

* I thank Steve Mason for his essential advice on an early version of this paper. I also thank Colin Green for rekindling my interest in this subject 
previous article. ${ }^{1}$ Synoptic comparison shows that these two passages share an ordered sequence of about two dozen concepts and have about a dozen word roots and some unusual vocabulary in common at parallel locations. On the other hand, even when expressing similar concepts, the passages exhibit many differences in vocabulary, syntax, and tone.

What can explain these correspondences interfused with differences? I observed that they might signify that an inventive Christian forger of the Testimonium was influenced by the Gospel of Luke; or they may simply be a series of chance resemblances arising from common traditions about Jesus. But the most provocative proposal, and the one most open to testing, is that Josephus wrote the Testimonium by paraphrasing a text very much like, if not identical to, the Emmaus excerpt. Regarding this proposal, James Carleton Paget observes it has advantages over other theories in explaining some of the Testimonium's language oddities, and the sharing of the basic structure can be the reason for the passage's puzzling brevity. ${ }^{2}$ Louis H. Feldman noted that the proposed use of a Christian text could be related to the great interest Josephus exhibits in Judaean religious and political movements. ${ }^{3}$ But these authors treat the proposal as only an interesting speculation, as does Fernando Bermejo-Rubio, who quotes John Meier's statement that all speculations about the Testimonium's source are equally unverifiable. ${ }^{4}$ And indeed, normal procedures of establishing source dependence require a greater amount of verbatim agreement than is present between the Testimonium and the Emmaus narrative. However, what has not been appreciated up to now is that there is a copious amount of research on Josephus's methods of paraphrase that can be brought to the examination of the texts. Not only the similarities but also the specific differences between the Testimonium and the Emmaus narrative could potentially be understood as products of Josephus's methods of modifying his sources. And if the Testimonium could be shown to be a Josephan paraphrase, one would have a solution to the long-standing question: Is the Testimonium

1 G. J. Goldberg, "The Coincidences of the Emmaus Narrative of Luke and the Testimonium of Josephus', The Journal for the Study of the Pseudepigrapha 13 (1995), pp. 59-77.

2 James Carleton Paget, 'Some Observations on Josephus and Christianity', in Jews, Christians and Jewish Christians in Antiquity (wUnT 251; Tübingen: Mohr Siebeck, 2010), pp. 185-265 (p. 237 n. 23o, p.256 n. 312).

3 Louis H. Feldman, 'On the Authenticity of the Testimonium Flavianum Attributed to Josephus', in Elisheva Carlebach and Jacob J. Schacter (eds.), New Perspectives on Jewish-Christian Relations: in Honor of David Berger (Brill, 2012), pp. 11-30 (18-19).

4 Fernando Bermejo-Rubio, 'Was the Hypothetical Vorlage of the Testimonium Flavianum a "Neutral" Text?', JSJ 45 (2014) pp. 326-365 (351, n. 118). 
indeed the earliest account of Jesus outside the New Testament, or is it instead a pious forgery? ${ }^{5}$

The Antiquities is, to a large extent, a book of paraphrases. The references that served as the basis for Books 1 through 13 are, in the main, still extant-including Hebrew, Greek and Aramaic versions of the Bible, the Letter of Aristeas and 1 Maccabees - and these have afforded researchers the ability to study in great detail Josephus's methods of adapting his sources. ${ }^{6}$ Embracing the traditions of Greek historiography, which expect accuracy combined with novelty of expression, Josephus typically chooses to follow his source quite carefully in its content, even to its sequence of facts; however, he will significantly recast its language. 'Occasional words and phrases are retained,' observes Shaye J. D. Cohen, regarding Greek sources, 'but, on the whole, the result is Josephan Greek, not a mechanical crib of the source.' ${ }^{7}$ Louis Feldman remarks Josephus 'almost pathologically' recasts his source's language to avoid being perceived as a mere copyist. ${ }^{8}$ In the process, Josephus will also elaborate or omit content to align with his own interests. But, 'It is particularly surprising,' writes Per Bilde, 'that this radical process of editing rarely interferes with the substance of the main sources, or alters the facts. ${ }^{9}$

In this article, I investigate the proposition that the similarities and differences between the Emmaus narrative and the Testimonium are consistent with Josephus's paraphrase style. In a phrase-by-phrase study, I compare each expression of the Testimonium to its analogue in the Emmaus narrative and then investigate, using existing research as well as novel database searches, if this association replicates a transformation observed to be employed by Josephus in his paraphrasing of material for the Antiquities. The investigation

5 Modern treatments of the authenticity debate, besides those already mentioned, include: John P. Meier, A Marginal Jew (Garden City, NY: Doubleday, 1991), pp. 56-78; Steve Mason, Josephus and the New Testament (Massachusetts: Hendrickson, 1992), pp. 163-175; Alice Whealey, Josephus on Jesus (Studies in Biblical Literature 36; New York: Peter Lang, 2003); Paget, 'Observations'; and Serge Bardet, Le Testimonium Flavianum (Josèphe et son temps 5; Paris: Cerf, 2002).

6 The sources for Books 14 through 17 are believed to include the history of Nicolaus of Damascus and other Greek historians, which only survive in fragments elsewhere, while those of Books 18 through 20, which deal with the first century, are largely unknown. The breadth of paraphrase studies is discussed in Shaye J.D. Cohen, Flavius Josephus in Galilee and Rome (Brill, 1979), pp. 25-47; Per Bilde, Flavius Josephus between Jerusalem and Rome (Sheffield Academic Press, 1988), pp. 98-99, pp. 191-200; and Feldman, Josephus and Modern Scholarship, pp. 392-419.

7 Cohen, Josephus in Galilee and Rome, p. 232. Cohen finds that "Josephus stands squarely in the Greek tradition' as exemplified by Livy's use of Polybius, Plutarch's rewriting of Dionysius of Halicarnassus, and others; see pp. 29-31.

8 Louis H. Feldman, Josephus's Interpretation of the Bible (Univ. of California, 1999), p. 31.

9 Per Bilde, Flavius Josephus, pp. 98-99. 
finds this to be the case for the majority of expressions. A comparison with other ancient accounts of Jesus demonstrates that this finding is highly unlikely to be due to chance. As a consequence of this study, I will submit that the Testimonium is indeed a paraphrase by Josephus of a text very like, or even identical to, the Emmaus narrative. This prospect, which I will call the paraphrase model, suggests there are natural and satisfying answers to the most puzzling questions about the Testimonium.

The central problem of the Testimonium is the apparent conflict between its authorship by a first-century Jewish historian and its Christian content. Beginning in the sixteenth century, commentators seeking to resolve this conflict have proposed that Christian scribes had either forged the Testimonium or had altered Josephus's original version. ${ }^{10}$ Yet the passage is attested with little variation in the Greek manuscript tradition, providing no evidence of meaningful tampering. ${ }^{11}$ While a full consideration of current theories is beyond the scope of this article, it seems fitting to briefly summarize their difficulties compared to the paraphrase model.

The proposal that the Testimonium is a complete forgery has the difficulty that the linguistic style of the passage is generally consistent with that of Josephus. ${ }^{12}$ This has been disputed, as there are also deviations from his style that have raised questions of authenticity; the paraphrase model, as will be seen, can account for these deviations in terms of influence from the Emmaus source.

The stylistic evidence has led to theories of partial editing. The most influential of these is the proposal of John Meier that the original text of Josephus can be retrieved if one deletes portions perceived to be overtly Christian in

10 The history is detailed by Whealey in Josephus on Jesus. Whealey determines that the first Christian allegation of total forgery was by Lucas Osiander in 1592 (pp. 92ff); the first to propose that a text by Josephus had been amended was Richard Montagu in 1642 (pp. 9899); and the first stylistic argument for authenticity was made in 1706 by Carolus Daubuz (p. 141).

11 Paget, 'Some Observations', pp. 209-223. Variations in Latin, Syriac and Arabic versions are explored by Whealey, Josephus on Jesus, p. 29; pp. 38-41; 185-192.

12 Meier, A Marginal Jew, pp. 8o-84; Paget, 'Some Observations', pp. 217-223. The possibility of a skillful Josephus imitator is discussed and judged unlikely by Serge Bardet, Le Testimonium Flavianum, pp. 110-123; 229. An argument that the style is actually that of Eusebius is presented by K. A. Olson, 'Eusebius and the "Testimonium Flavianum”, CBQ 61 Num. 2 (April 1999), pp. 305-322; this is critiqued by Paget, 'Some Observations,' pp. 221-223, and Alice Whealey, 'Josephus, Eusebius of Caesarea and the Testimonium Flavianum', in Christfried Böttrich and Jens Herzer (eds.), Josephus und das Neue Testament (wUNT 2og; Tübingen: Mohr Siebeck, 2007), pp. 73-116. 
content, amounting to a third of the passage (29 out of 89 words). ${ }^{13}$ A major criticism of this proposal is that the selection methodology is based not on an objective foundation, but on suppositions about Josephus's comprehension and suspicion of Christian history. ${ }^{14}$ Differences in these assumptions have thus led to many competing theories for altering the received text. In contrast, the paraphrase approach relies only on a comparison of texts. The presence of Christian elements is resolved with the solution that it was Josephus who revised the text of a Christian author, rather than the reverse. This solution would eliminate much of the need to speculate on later Christian expansions. For example, Meier's reconstruction simply produces a subset of the paraphrase model text, but Meier's largest interpolation, the resurrection sentence, is seamlessly compatible with the rest of the paraphrase (see below, sections $\mathrm{C}_{22}-\mathrm{C}_{31}$ ). It strains credulity that this can be an accident of later interpolation. The paraphrase model also has greater explanatory power, in that the proposed source provides insights into the origin of each phrase of the Testimonium - a difficult task for interpolation theories, which struggle with such matters as the brevity of the Testimonium, its overall kerygmatic structure, ${ }^{15}$ and its silence on critical matters; through the proposed paraphrase, these are readily understood as reflections of the Emmaus source.

Above all, the current theories are faced with the prospect that the entire Testimonium is consistent with Josephus's paraphrase style as well as his writing style. The Alternative Explanations section of this article considers how the theories could respond to this challenge.

In the Concluding Remarks, I provide some thoughts on the implications of the paraphrase model for the study of the historical Jesus and Josephus's interaction with Christianity.

\section{The Paraphrase Study}

The following study asks two questions for each phrase in the Emmaus excerpt: 'Is this concept represented in a Testimonium expression at a similar position?

13 Meier, A Marginal Jew, pp. $5^{6-78 .}$

14 Paget, 'Some Observations', pp. 234-237. Bermejo-Rubio,'Vorlage', argues at length against Meier's proposal.

15 Hans Conzelmann, Jesus (Fortress Press, 1973), pp. 13-14; Paul J. Hopper, 'A Narrative Anomaly in Josephus: Jewish Antiquities xviii:63', in Monika Fludernik and Daniel Jacob (eds.), Linguistics and Literary Studies: Interfaces, Encounters, Transfers (Berlin: de Gruyter, 2014), pp. 147-169. 
If so, is there evidence in Josephus's sources and works that he would revise the Emmaus vocabulary into that seen in the Testimonium?'

The study seeks source-to-Antiquities transformations in Josephus's paraphrase that exemplify these revisions. It is to be understood that the source-to-Antiquities transformations thus found are not unique, as Josephus has a number of different ways of dealing with particular source words, including omission. The study can only establish that Josephus has at times made a particular transformation, not that he must.

An important limiting factor is that some Emmaus expressions have little or no representation in Josephus's other sources, so there can be no paraphrase parallels. In these cases, the study will examine if he associates similar expressions within his own works with the vocabulary used in the Testimonium. These associations are necessarily weaker evidence than direct paraphrase, but address the same question as to whether Josephus would rewrite a phrase a certain way.

For brevity, the Testimonium will be referred to as the ' $\mathrm{TF}$ ', and the Emmaus excerpt as simply 'Emmaus.'

Out of necessity, the study uses the text from the Gospel of Luke, without demanding that the Gospel must have been the actual source. I will remark on manuscript variations of either passage when they may bear on the discussion. ${ }^{16}$

\section{Preservation of Ordered Content}

In the study that follows, I have aligned the texts to display phrases where the TF could arguably be based, at least in part, on the same underlying concept, or logical template, as Emmaus. In the discussion, these correspondences are numbered $\mathrm{C} 1, \mathrm{C} 2$, and so on.

As will be seen, the study identifies thirty-one shared concepts at analogous positions in the Emmaus narrative and the TF. These concepts comprise almost the entirety of the TF.

16 The Greek text of Luke used in this article is that of the 28th edition of Nestle-Aland. The Greek text of the Testimonium is Benedikt Niese's, in Louis H. Feldman, Josephus: Jewish Antiquities, Books XVIII-XIX (Cambridge, MA:Harvard, Loeb Classical Library, 1965). Greek and Latin variations are given by Levenson and Thomas R. Martin,The Latin Translations of Josephus on Jesus, John the Baptist and James: Critical Texts', JSJ Vol. 45, No. 1 (2015) pp. 1-79. For Josephus's sources, the Rahlfs Septuagint, 9th edition, and Pelletier's Letter of Aristeas (cited below) were searched with the Thesaurus Linguae Graecae, http://stephanus. tlg.uci.edu. [accessed Jan-Nov, 2020]. Steve Mason's valuable PACE website facilitated the study of the Brill Josephus volumes; Project on Ancient Cultural Achievement, http://pace. hypervisions.it/york/york/texts.htm [accessed Jan-Nov 2020]. 
As noted in the introduction, this structure-vocabulary changes within a general preservation of ordered content-is the primary characteristic of Josephus's paraphrases when a reference text meets his needs.

\section{Content Modifications}

Josephus's paraphrases can exhibit changes in content to achieve certain characteristic goals. These changes can be grouped, following Christopher Begg, into three categories: rearrangements, omissions/condensations, and additions/expansions. ${ }^{17}$ Josephus's motives in making alterations are collected in the two volumes by Louis Feldman on Josephus's rewriting of the Bible. ${ }^{18}$ The major content differences are discussed in the following study, where it is seen they can all be understood in terms of these known motives.

\section{Linguistic Modifications}

To study linguistic modifications, it is often necessary to employ the portions of the Antiquities that are known to be based on Greek texts, rather than on the Hebrew or Aramaic Bibles. The most unambiguous Greek source is the Letter of Aristeas, which is paraphrased in Ant. 12.7-12.118; André Pelletier has performed a careful comparison of these texts. ${ }^{19}$ Karl-Friedrich Pohlmann has shown Josephus's close dependence on 1 Esdras (in Ant. 11.1-158), ${ }^{20}$ and numerous writers have identified a similar reliance on 1 Maccabees (Ant. 12.24013.214). ${ }^{21}$ In addition, for some biblical books Josephus is believed to have relied primarily on the Septuagint, e.g., Kings and Chronicles; many of these revisions have been analyzed by Christopher Begg. ${ }^{22}$ Also useful are Josephus's revisions of his own earlier writing in the Judean War.

17 The categories are identified in Christopher T. Begg, Josephus' Story of the Later Monarchy (AJ 9,1-10, 185) (Leuven University Press, 2000), p. 105.

18 Louis H. Feldman, Josephus's Interpretation of the Bible and Studies in Josephus' Rewritten Bible (Brill, 1998). Studies has a useful summary of motives on pp. 538-570. A valuable resource is Feldman's commentary throughout Flavius Josephus: Translation and Commentary, Vol. 3: Judean Antiquities 1-4, ed. Steve Mason (Brill, 2000).

19 André Pelletier, Flavius Josèphe adaptateur de la Lettre d'Aristée (Paris: Klincksieck, 1962),

20 Karl-Friedrich Pohlmann compares 1 Esdras with in Studien zum dritten Esra. Ein Beitrag zur Frage nach dem ursprunglichen Schluss des chronistischen Geschichstswerkes. FRLANT 104 (Vandenhoeck \& Ruprecht, 1970) pp. 74-126.

21 A review is Isaiah M. Gafni, 'Josephus and 1 Maccabees', in Louis H. Feldman and Gohei Hata (eds.), Josephus, the Bible, and History, (Detroit: Wayne State University, 1988), pp. 115-131.

22 Christopher T. Begg, Josephus' Account of the Early Divided Monarchy (Aj 8,212-420) (Leuven University Press, 1993) and Josephus' Story of the Later Monarchy; with Paul Spilsbury, Flavius Josephus: Translation and Commentary, Volume 5:Judean Antiquities 8-10, ed. by Steve Mason (Brill, 2000). 
The modifications fall into three categories. First are the shared word roots: Josephus's revisions typically retain a few words from their sources, often with a change in inflection or conversion into a cognate. ${ }^{23}$ Out of the thirty-one correspondences, the following discussion reveals twelve shared word roots in the proper context; each adaptation has paraphrase support. Next are substitutions with direct paraphrase support: I find there are eight expression substitutions in Emmaus-TF that have identifiable precedents in source-to-Antiquities paraphrases. Then there are substitutions with indirect support: there are at least eight correspondences that do not have clear paraphrase parallels, but which are seen in Josephus's writings as expression pairs that he treats as near synonyms. Last are replacements with little or no support: the remaining three pairs have less explicit evidence of association, but do employ Josephan language. The expression pairs in these four categories are listed in the Summary.

\section{Emmaus-TF Parallels in the Antiquities}

In the following, the passages are compared in table format, sentence by sentence. On the left is Emmaus and on the right is the TF, with somewhat literal translations beneath. Expressions are compared in order except for a few displacements, which are indicated by an asterisk in the discussion heading. Citations of sources and their paraphrases are of the form Aristeas 27/Ant. 12.33, with the source always on the left of the slash; when there are multiple examples from the same pair of works, the names of the works are not repeated: for example, 'Aristeas 27/Ant. 12.33, 33/12.40, 53/12.61' are three citations of Letter of Aristeas texts and their Antiquities paraphrases.
Lk. 24.18-19
Ant. 18.63

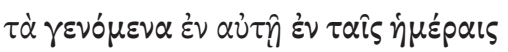

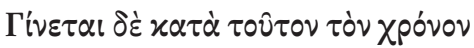

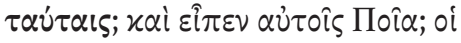
'Iทб०טิs,

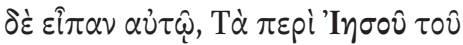

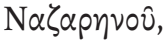

23 Cohen, Josephus in Galilee and Rome, pp. 232-233; see also pp. 29-31. 

Lk. 24.18-19
Ant. 18.63

The things happening in it in these

There happens about this time Jesus, days - And he said to them, What things?-And they said to him, the things about Jesus the Nazarene,

\section{(Omission) Dialog Framework}

The TF does not use the framework of a conversation on the road. Yet it conveys the core of what was said. There is a parallel in Josephus's treatment of the Letter of Aristeas. As Pelletier points out, Josephus extracted the substance of Aristeas's letter to a companion and erased all the elements that would recall a written conversation with a friend. ${ }^{24}$

\section{(C1) happens ( $\gamma \varepsilon v o ́ \mu \varepsilon \nu \alpha / \Gamma i v \varepsilon \tau \alpha l)$}

The verb yivoual (happen, become) appears in both texts but in different inflections: in the Emmaus excerpt, 'the things that have happened' ( $\tau \dot{\alpha} \gamma \varepsilon v o ́ \mu \varepsilon v \alpha)$,

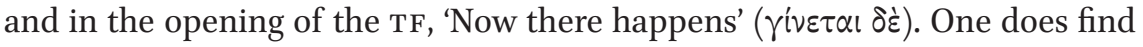

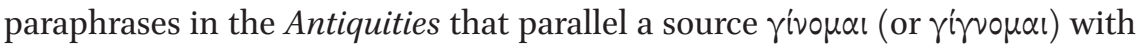
inflection changes. There are at least eight such instances from the Letter of Aristeas: Aristeas 27/Ant. 12.33, 33/12.40, 53/12.61, 81/12.83, 182/12.95, 293/12.102, 308/12.108, 314/12.112. And there are three from 1 Esdras: 1 Esdr. 8.22/Ant.11.128, 8.27/11.131, 9.3/11.148.

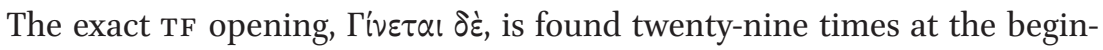
nings of sentences in his works, but only three fall in Antiquities passages where sources are available. Two of these are derived from sources that, in the Septuagint version, do have 'happens/becomes' (although with the connotation of birth). ${ }^{25}$ The most similar revision is Gen. $21.2-7$, 'the son that had come

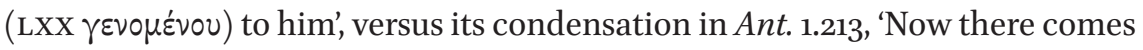
( $\Gamma \dot{i} v \varepsilon \tau \alpha \iota \delta \grave{\varepsilon}$ ) to Abraham a son'. The inflection change-aorist participle to present indicative - and shift in position to the head of the sentence is formally nearly identical to the Emmaus-TF difference. In the second example, the revision of Gen. 36.4-5 to Ant. 2.4, ह่ үर́vovto is given a similar treatment.

\footnotetext{
24 Pelletier, Lettre d'Aristée, p. 252.

25 The third instance, Ant. 3.134, combining Ex. 37.1-9 and Deut. 10.1-5, appears to introduce 'happens/comes' to mask a contradiction as to the maker of the ark; Feldman, Judean Antiquities 3.134, n. 315 .
} 


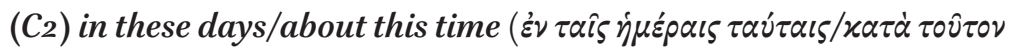

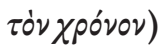

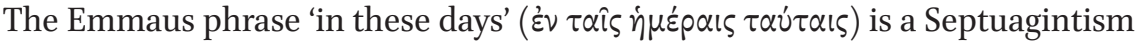
that Josephus regularly translates into the classical 'about this time' ( $\varkappa \alpha \tau \dot{\alpha}$

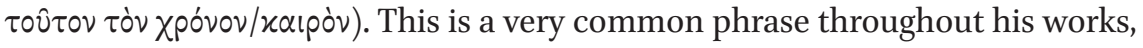
with xalpov more frequent in the portions of the Antiquities where sources can be compared. ${ }^{26}$ Comparable to Emmaus is 1 Macc. 2.1, 'in those days' ( $\dot{\varepsilon} v$

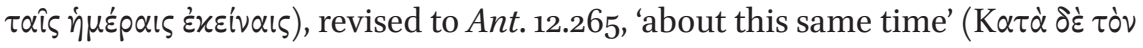
à่tòv xalpòv). Similar is 1 Macc. 1.11/Ant. 12.237. The same rendering is seen in LXX 1 Samuel 28.1 (мт bayamim hahem)/Ant. 6.325 and LXX 2 Chron. 21.8/Ant. $9 \cdot 97 \cdot{ }^{27}$

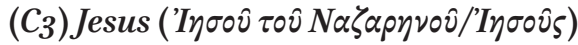

Where Emmaus has 'Jesus the Nazarene', the TF uses simply 'Jesus'. Analogous is the removal of the gentilic 'Hittite' from 'Uriah the Hittite' in the conversion of 2 Samuel 11.6 to Ant. 7.131. Alternatively, 'Ephron the Hittite' becomes 'a certain Ephron' (Gen. 23.10/Ant. 1.237), with the replacement by $\tau \iota \varsigma$; several TF manuscripts similarly read 'a certain Jesus' ('I scholars consider likely originated with Josephus. ${ }^{28}$

Lk. 24.19 Ant. 18.63

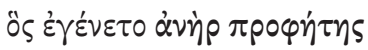

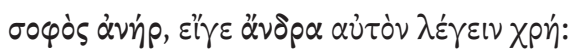

who was a prophet man

a wise man, if one ought to call him a man;

\section{(C4) $\operatorname{man}(\dot{\alpha} v \dot{\gamma} \rho)$}

Not unexpectedly, Josephus often retains the word 'man' ( $\alpha \eta \dot{\eta} \rho)$ from his sources. Aristeas has many examples, usually in the plural: Aristeas $3^{1 / A n t .}$ $12.38,39 / 12.49,43 / 12.53,179 / 12.92,183 / 12.96$, etc.

26 Exact matches to the TF phrase (with Xpóvov) are Ant. 13.46, 17.19, 18.39, 18.80. D. Schwartz, 'KATA TOYTON TON KAIPON: Josephus's Source on Agrippa II' JQR 62 (1982), pp. 241-268. (248); Steve Mason, Flavius Josephus on the Pharisees, (Brill, 1991), p. 200.

27 On Josephus's use of LXx for Samuel and Chronicles, see Feldman, Interpretation, pp. $3^{2-34}$ and pp. 34-35.

28 Levenson and Martin,'Critical Texts', p. 21 n. 114; Bermejo-Rubio, 'Vorlage', pp. 357-8. 


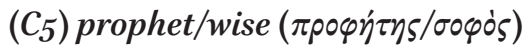

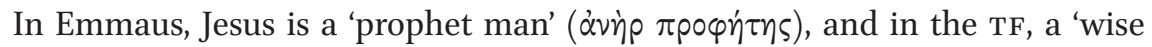

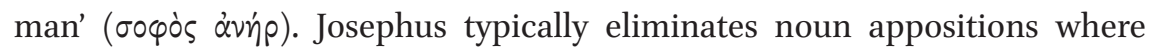
they appear in his biblical sources. For example, 'warrior man' (LXx àvip

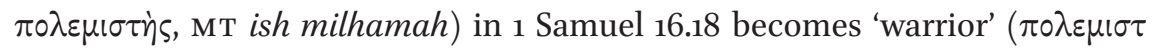

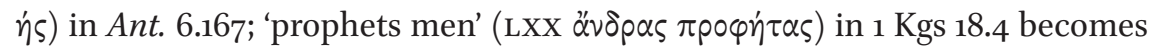
'prophets' in Ant. 8.330 (although this may directly reflect the мт nevi'im). This treatment applied to the Emmaus expression would have produced 'prophet'. But it is well established that Josephus avoids using 'prophet' for persons who lived after the biblical era. ${ }^{29}$

There are no biblical verses where Josephus alters 'prophet' to 'wise', but biblical prophets do not present the problem of the Emmaus text; what are relevant are post-biblical Antiquities sources, and none of these use 'prophet'. As described earlier (under 'The Paraphrase Study'), in cases where source representation is lacking, I instead ask if he elsewhere associates the words 'prophet' and 'wise'. One does see this association, for example, in reference Daniel, whom he calls both a 'wise man' (Ant. 10.237, drawn from Dan. 5.11) and a 'prophet' (Ant. 10.268, without biblical precedent). ${ }^{30}$ Josephus both associates and distinguishes these terms. He does tell us that 'wisdom' among his people is only credited to scholars capable of interpreting the Holy Scriptures (Ant. 20.264). What distinguishes a 'prophet', on the other hand, as seen throughout his writings, is a power that comes directly from the divine spirit. ${ }^{31}$ If he did alter the Emmaus 'prophet' to 'wise', then, he did not transmit the source with complete faithfulness; the implication would be that Josephus had a separate understanding of Jesus as a learned interpreter of Scripture. Perhaps that is why the next phrase could be interpreted as Josephus apologizing for inaccurately rendering his source.

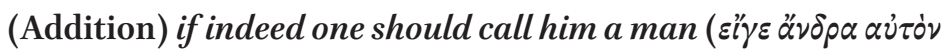 $\left.\lambda \varepsilon^{\prime} \gamma \varepsilon \imath \nu \rho \eta^{\prime}\right)$}

The remark 'if indeed one should call him a man' has no explicit parallel in Emmaus. Although often considered a forgery, similar vocabulary is used by

29 Feldman, 'Prophets and Prophecy in Josephus', JTS 41 (1990), pp. 386-422 [404-407]; Interpretation, p. 6 o.

30 Feldman, Interpretation, p. 57. Josephus elsewhere applies 'wise man' only to Daniel and Solomon, in both cases drawing from his sources: Dan. 5.11/Ant. 10.237 and 1 Kgs 5.7/Ant. 8.53 .

For the debate on this phrase, see Vermes, Jesus in His Jewish Context, pp. 92-93; Meier, Marginal Jew, p. 81 n. 41.

31 Begg and Spilsbury, Judean Antiquities 8-10, Ant. 10.189 n. 769; on the 'divine spirit,' Ant. 10.239 n. 1026; Ant. 10.195 n. 829. 
Josephus in, for example, War 3.391, 'whether one should say by fortune' ( $\varepsilon i ا \tau \varepsilon$

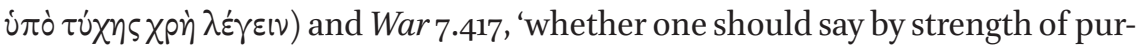
pose'. Josephus frequently makes comparable additions to his sources, when he makes 'gestures of courtesy' to show concern for opinions differing from his own convictions; on the parting of the red sea he remarks 'let each have their own opinion' (Ant. 2.348), and similarly in Ant. 1.108 (biblical lifespans), 3.81 (Sinai wonders), and many more. ${ }^{32}$ While Meier ${ }^{33}$ reads this statement as a matter of faith, for Josephus, not living in a Christian-dominated world, it is a matter of Judean history: whether Jesus should be called instead a 'prophet man' or something else was a question Josephus, in the absence of evidence, could not decide for his Roman readers.

Lk. 24.19

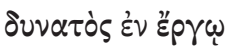

mighty in deed

xai $\lambda \dot{\gamma} \gamma \omega$

and word

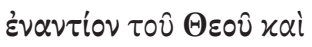

$\pi \alpha \nu \tau \dot{s} \varsigma \tau 0 \hat{v} \lambda \alpha \circ \hat{v}$,

before God and all the people,
Ant. 18.63

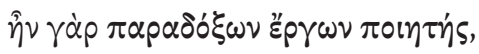

For he was a worker of surprising deeds

$\delta 1 \delta \dot{\alpha \sigma} \sigma \alpha \alpha \lambda \circ \varsigma$

a teacher

$\dot{\alpha} \nu \theta \rho \omega \dot{\pi} \pi \omega \nu \tau \hat{\omega} \nu \dot{\eta} \delta \circ \nu \hat{\eta} \tau \dot{\alpha} \lambda \eta \theta \hat{\eta} \delta \varepsilon \chi \propto \mu \varepsilon \dot{\varepsilon} \nu \omega \nu$,

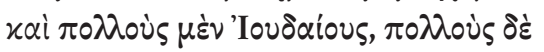

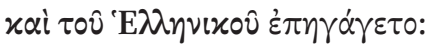

of people such as received the truth with pleasure, and he won over many Jews as well as many of the Greeks;

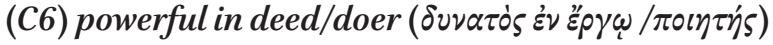

Emmaus elucidates 'prophet man' with 'powerful in deed and word'. The TF similarly expands wise man with an analogous pair of concepts: a 'doer'

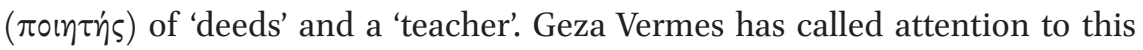

32 Feldman, Interpretation, pp. 209-210; Cohen, Josephus in Galilee and Rome, p. 39. 'gesture of courtesy' is George MacRae's term, Begg and Spilsbury, Judean Antiquities 8-10, 10.281 n. 1192.

Meier, Marginal Jew, p. 6 o. 
similarity between Lk. 24.19 and the TF; he has proposed that the shared depiction of Jesus as a wonder-worker and teacher recalls 'the earliest, pre-Pauline Judaeo-Christian portrait' of Jesus as a prophet. ${ }^{34}$

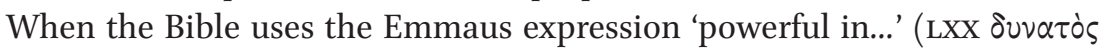
$\varepsilon$ ¿ $v$...), Josephus endeavors to capture its underlying connotations (e.g., 'hoplites', 2 Chr. 25.6/Ant. 9.188); but there are no cases where he revises 'powerful'

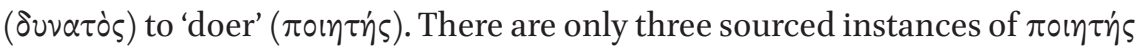
in the Antiquities, and these are all copied from Aristeas and signify 'poet'. ${ }^{35}$ The verb 'to do/make' ( $\left.\pi \circ \varepsilon^{\varepsilon} \omega\right)$, however, occurs over a thousand times in the Antiquities and is used to connote any ability, as well as in conjunction with 'deed' (e.g., Ant. 6.243, 1.306). In an example that shows Josephus can link it

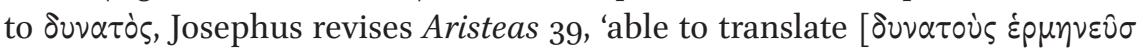

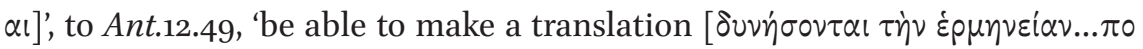
เทं $\sigma \sigma \theta \alpha l]$ '.

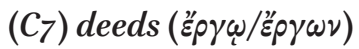

Emmaus 'deed' is paralleled by the TF 'deeds' with an inflection change, dative singular to genitive plural ( $\varepsilon^{\prime} p \gamma \omega$ to ép $(\omega v)$. In the Antiquities, there are several examples where हैprov is lifted from the Greek sources with an inflection change. In the conversion of Aristeas 81 to Ant. 12.84, Josephus changes its case from the genitive to the dative. Other precedents are 1 Macc. 2.51/Ant. 12.282, 1 Esdr. 9.11/Ant. 11.15o, and 1 Esdr. 7.2/Ant. 11.105.

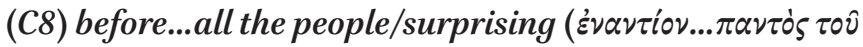 $\lambda \alpha 0 \hat{v} / \pi \alpha \rho \alpha \delta \circ \hat{\xi} \omega \nu)$}

Feldman has drawn attention to Josephus's strong 'psychologizing tendency', the inclination to add thoughts and emotions that are only implied in the source. ${ }^{36}$ Thus, where the Bible has an expression only denoting observation, such as Emmaus's 'before all the people', Josephus will often substitute the people's reaction, including the TF's 'surprising' ( $\left.\pi \alpha \alpha_{\alpha} \delta \circ \circ \xi_{0 \varsigma}\right) .{ }^{37}$ At Ex. 17.6, Moses

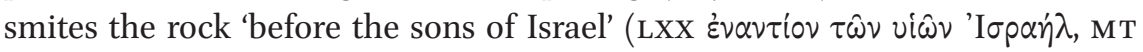
l'ene ziqne yisrael), while in Ant. 3.38 Josephus substitutes 'they were astounded at the surprising [ $\pi \alpha \rho \alpha \delta \delta \xi \omega]$ ] happening.' Where 'Aaron...performed the signs

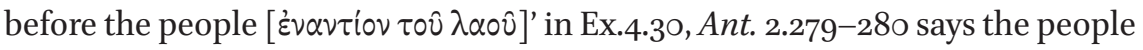

34 Vermes, Jesus in His Jewish Context, pp. 93-98.

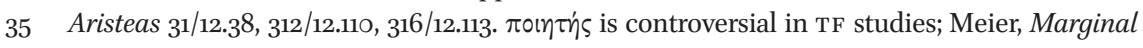
Jew, p. 81, n. 41 .

36 Feldman, Interpretation, pp. 197-204.

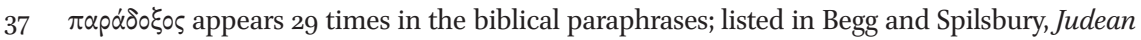
Antiquities 8-10, 10.266 n. 1118. 
were amazed at 'the surprising things shown to them' ( $\tau \hat{\omega} \nu \pi \alpha \rho \dot{\alpha} \delta \delta$ ' $\xi \alpha \nu$ a $\tau_{\tau o i}$

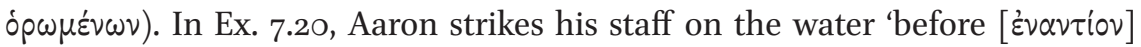
Pharoah and before his servants'; Josephus omits the latter phrase and instead states that Pharoah was 'at a loss to explain this astonishing [ $\pi \alpha \rho \alpha \dot{\delta} \circ \xi \circ v]$ thing' (Ant. 2.295). The same association of 'before/surprising' is seen in Ex. 7.9/Ant. 2.285 (rod to serpent). Conceptually related is $2 \mathrm{Kgs} 6.20$ ('they saw') versus Ant. 9.58, recalled at Ant. 9.182 as Elisha's 'surprising deeds'. ${ }^{38}$

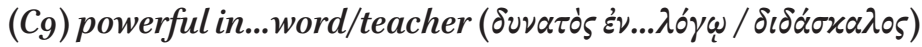

Emmaus's 'powerful...in word' is mirrored by the TF 'teacher'. There are only two instances of 'teacher' ( $\delta 1 \delta \alpha \sigma \kappa \alpha \lambda \circ \varsigma)$ in the Antiquities' biblical paraphrases, and their sources are not known. ${ }^{39}$ However, there are many Antiquities instances of the verb 'teach' $(\delta 1 \delta \dot{\alpha} \sigma \kappa \omega)$, and six of these cases substitute for the source's 'speak' or 'say': Gen. 12.13/Ant. 1.163, Ex. 20.1/3.91, Num. 28.1/4.311, 1 Sam. 25.5/6.296, 2 Chron. 33.16/10.43, 1 Esdr. 4.13/11.49. For example, 1 Esdr. 4.13, 'had spoken about women and truth', becomes Ant. 11.49, 'to teach them about women and truth'. To specify Jesus's speech as teaching, however, Josephus would have needed information beyond Emmaus.

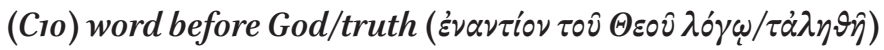

There are only a few biblical instances comparable to the Emmaus 'word before God,' and although Josephus interprets these in the sense of testifying to truth, he does not use the TF word 'truth'. For example, Deut. 26.13, 'you

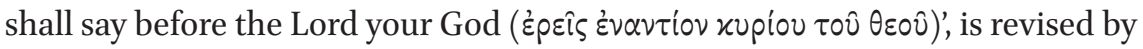

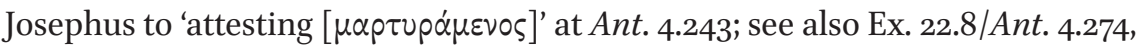
1 Sam. 12.3/Ant. 6.86.

But in the context of a prophet's words, as in Emmaus, the better comparison may be the much more common biblical expression, 'spoken by the word of the Lord'. Josephus does rewrite these with 'truth'. Thus 1 Kings 13.32, 'come to pass what he spoke by the word of the Lord' (o $\dot{\varepsilon} \lambda \dot{\alpha} \lambda \eta \sigma \varepsilon \nu$ हे $\lambda \hat{o} \gamma \omega$ Kupiov), becomes Ant. 8.242, 'everything that he prophesied...was true [ $\alpha \lambda \eta \theta \hat{\eta}]$.' So also, 1 Kings 22.38/Ant. 8.417, 1 Kings 13.5/Ant. 8.234, 2 Kgs 1.16/Ant. 9.26, (мт) Jer. $37.6 /$ Ant. 10.112 , $^{40}$ and many others. And throughout his work, Josephus associates God with truth, e.g., Ant. 11.55.

38 Eusebius' usage of doer of surprising deeds has been taken as evidence he authored the TF; Olson, 'Eusebius', p. 311. But Eusebius can have adopted the phrase from Josephus, as its earliest appearances are in preliminaries to TF citations (Dem. Ev. 3, Hist. Eccl. 1). See Paget, 'Observations,' p. 221, and Whealey, 'Josephus, Eusebius', pp. 8o-84.

39 Feldman, Judean Antiquities, 1.61 n. 129-131; 3.49 n. 96-97.

40 On Jeremiah 10.112, see Begg, 'Later Monarchy', pp. 545-547. 
In the TF, Jesus's words are not claimed to be true, only that he had followers who enjoyed truth. For this detail, as with 'teacher', Josephus would have probably needed another source.

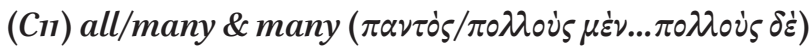

When 'all' in a biblical verse is excessive, Josephus finds a more reasonable

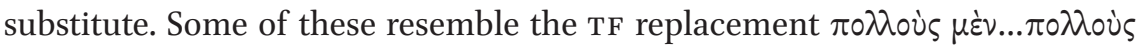
$\delta$ غ̇. In 1 Kings 9.11 Hiram assisted Solomon 'with gold and all that he wished for' ('่v $\pi \alpha \nu \tau i \quad \theta \varepsilon \lambda \dot{\eta} \mu \alpha \tau \iota \alpha \dot{\tau} \tau 0 \hat{)})$, while Josephus in Ant. 8.141 writes that Hiram

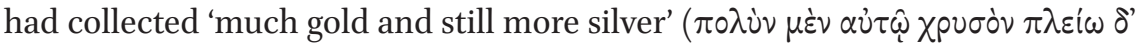
áprupov). A similar expression replaces the copious plunder of 'all ( $\pi \dot{\alpha} \sigma \alpha \varsigma)$ the cities' in 2 Chr 14.14/Ant. 8.294. For quantities other than 'all', Josephus adds this type of construction in 2 Sam. 15.1/Ant. 7.194 (identical to the TF form), 1 Chr 29.1/Ant. 7.377, 2 Kings 7.8/Ant. 9.85, and 1 Macc 3.10/Ant. 12.287.

When 'all the people' is clearly unrealistic - as it is in Emmaus-Josephus uses instead 'most' (oi $\pi \lambda$ gíous) as in 1 Sam. 13.22/Ant. 6.105), or 'the multitude'

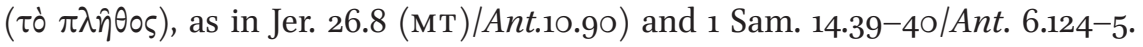
But there is no example where Josephus divides 'all' into two ethnic groups, as in the TF. But for an implausibly large number other than 'all', there is a close parallel found in Josephus's revision of his own prior work: the perhaps unbelievable 'six thousand colonists' in War 1.403 are divided, in Ant. 15.296, into

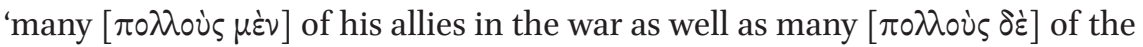
neighboring populations'.

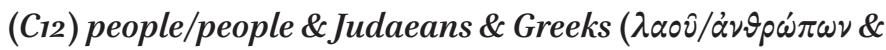

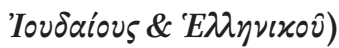

Where Emmaus states Jesus' audience is all the 'people' $(\lambda \alpha \circ \hat{)})$, the TF characterizes, first, the 'people' ( $\dot{\alpha} \nu \rho \rho \dot{\omega} \pi \omega \nu)$ who enjoyed hearing truth, and then the diversity of his followers, 'Judaeans and 'Greeks'. As the latter has little gospel support, it has been proposed that Josephus has drawn on his own knowledge of the mixed composition of the Jewish-Christian community in Rome. ${ }^{41}$

\section{$\left(C_{13}\right)$ powerful...before all \& we were hoping */won over ( $\left.\dot{\eta} \lambda \pi i \zeta o \mu \varepsilon \nu / \varepsilon \dot{\pi} \pi \eta \dot{\alpha}^{\prime} \gamma \varepsilon \tau 0\right)$}

(The asterisk indicates displacement.) The opinion of Jesus' Emmaus audience that 'we were hoping he would liberate Israel' establishes he had firm followers, which is also implied by his powerful speaking ability. Josephus appears

41 Whealey, Josephus on Jesus, p. 27; Meier, Marginal Jew, pp. 64-65. 


\section{Lk. 24.26 (displaced from below) Ant. 18.63}

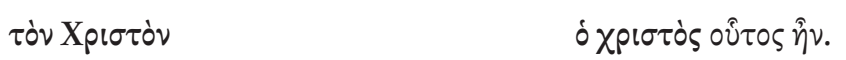

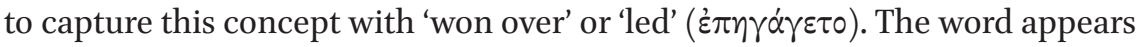
over one hundred times in his works, but there are no known instances where it replaces the Emmaus $\dot{\eta} \lambda \pi i \zeta o \mu \varepsilon v$; the latter occurs only nine times in his LXX sources (see $\mathrm{C} 2 \mathrm{O}$ ). The displacement is discussed in the next section.

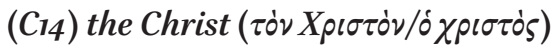

When his biblical source contains 'the Lord's anointed', Josephus never adopts

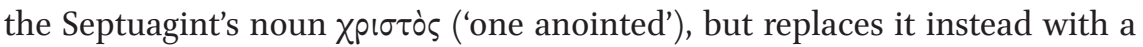
more common expression, such as 'appointed by God'. ${ }^{42}$ He does use the verb 'anoint' $(\chi p i \omega)$ ten times in kingship ceremonies where he makes clear its function, and at least once he avoids $\chi$ pi $\sigma \tau$ ò $\zeta$ by using the verb instead. Because he had a standard way of rendering it that elucidates its sense, not doing so for the TF would indicate Christos was a term with its own significance to his readers and cannot be avoided. The meaning of Christos to the average Roman reader of Josephus in the gos CE might be gleaned from Tacitus, writing some two decades later (Ann. 15.44), which indicates then Josephus's readers would have been aware that the Christians had been named after a real person in Judea, Christos. It isn't unreasonable to suppose Josephus composed the TF with the majority of his readers in mind.

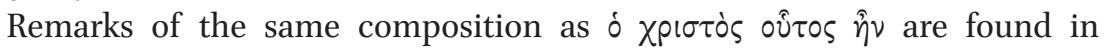
Josephus's works. ${ }^{43}$ Examples are Ant. 20.179, 'This was Phabi's son' ( $\Phi \alpha \beta \varepsilon \imath$ $\pi \alpha \hat{\imath} \varsigma$

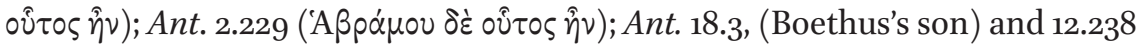
(Onias' brother); and, with regard to titles, Ant. 19.301, 'This was the ruler of

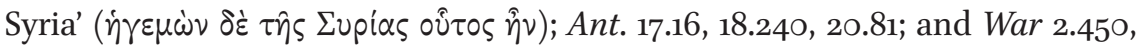

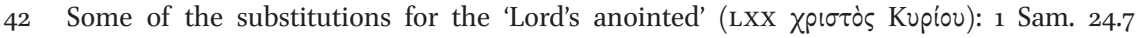
(LXX)/Ant. 6.284 'the one found worthy of kingship by God;' 1 Sam. 26.11/Ant. 6.312 'the king who had been appointed by God;' similarly 2 Sam. 19.21/Ant. 7.265. In revising 1 Sam. 16.6, Ant. 6.159 replaces the noun with the verb, 'anoint'. On Josephus's preference not to discuss a royal messiah, see Feldman, Studies, pp. 382-389, 554-555; Interpretation, pp. 151-154.

Some are noted by Paget, 'Some Observations', p. 220 n. 151.
} 
$6.305,7.216$. These are always Josephus's phrasing and not present in his source. Thus, stylistically, this phrase is consistent with a revision by Josephus.

The presence of the definite article coupled with a familiarity with Christian history has led most translators to render the TF's o Xpı or even 'the Messiah,' even though it can also be taken as a name, in accordance with definite article usage in Greek. The proposal that Christos in the TF is simply intended to be understood as a personal name goes back at least to William Whiston. ${ }^{44}$ The question is whether the article originated with Emmaus, where it also appears. Pelletier has studied the question of whether Josephus follows his source in using the definite article. Where the Letter of Aristeas includes the definite article with the name of a person, Pelletier has found that, ninety percent of the time, Josephus also does so in his corresponding paraphrase. 'The Demetrios' ( $\dot{\delta} \Delta \eta \mu \eta \dot{\tau} \tau 10 \varsigma$ ), for example, appears twice in Aristeas (301 and 308 ), and is copied both times by Josephus (Ant. 12.103 and 12.107). Pelletier gives 10 such examples, including Aristeas 304/12.105 ('the' Dorotheus) and 41/12.51 ('the' Eleazar), while only once is Aristeas's article omitted. Conversely, in sixteen out of the seventeen instances where Aristeas does not use the definite article, Josephus again follows suit. ${ }^{45}$ This practice shows Josephus would have no problem with copying the article from Emmaus while allowing the $\mathrm{TF}$ phrase to be understood as 'This was Christos', in which he calls on the reader's recognition of the name.

I will comment here on just two of the questions that have been raised concerning this phrase. Many commentators have noted it seems out of context, which some have taken as evidence of interpolation, others of genuineness. ${ }^{46} \mathrm{I}$ note that Emmaus has two descriptions of the followers' opinion of Jesus, that

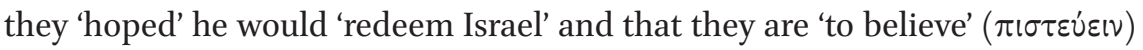
the prophecies that he was 'the Christ'. It would have been characteristic for Josephus to condense these and group them thematically with his remark about Jesus's teaching a receptive audience. ${ }^{47}$ This process can have led to $\mathrm{C}_{12}, \mathrm{C}_{13}$ and the Christos phrase in their current locations. I discuss further the 'redeem Israel' phrase below (after C20).

44 Whiston, Diss. 1, Obs. III. Bardet agrees and cites a number of scholars supporting this position in Le Testimonium Flavianum, pp. 105-107. Bermejo-Rubio, 'Vorlage', p. 334 n. 32, similarly cites Nodet.

45 Pelletier, Lettre d'Aristée, p. 208-209.

46 Meier, Marginal Jew, p. 6o; Whealey, Josephus on Jesus, p. 42 Paget, 'Some Observations', p. 220-221.

47 Cohen, Josephus in Galilee and Rome, pp. 42-43. An example of a similar small displacement is the shift of 2 Chr. 24.7 to 24.5 in creating Ant. 9.161; Begg, Later Monarchy, pp. 205-206. 
This leads to the next question. Jerome's Latin version of the Testimonium (De viris illustribus 13) translates as, 'He had many Judeans and gentiles as his followers and was believed to be [credebatur esse] Christus.' ${ }^{\text {'8 }}$ Many commentators have proposed that this may reflect an original form of the TF and that a later Christian editor removed 'believed to be.49 As just noted, Emmaus also has 'believe' in association with Christos, suggesting Josephus can have adopted it and arrived at the construction referenced by Jerome. If so, however, there are reasons to conjecture that Josephus himself was the one to later alter the text. First, the received text conforms to his style. More significantly, Jerome's version does not make much sense outside of Jewish and Christian circles. For if the majority of Josephus's readers did indeed consider Christos to be the name of a historical person, then they would be perplexed by the assertion that one real person (Jesus) was 'believed to be' another real person (Christos). A puzzled audience response in public readings, then, can have led Josephus to make the most expedient change, the removal of 'believed to be' before official publication. While a better solution may have been 'he was called ho Christos,' similar to Ant. 20.200, ${ }^{50}$ this has neither textural witnesses nor support as an Emmaus paraphrase; and it still requires the activity of an unknown editor to obtain the current text. If Jerome's does represent an earlier version, the proposal of a final edit by Josephus is the parsimonious solution.

\section{Lk. 24.20 Ant. 18.64}

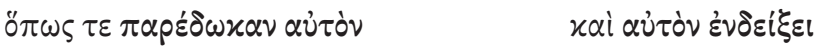

and how delivered him

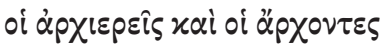

the chief prices and leaders

$\dot{\eta} \mu \hat{\omega} \nu$

of us
And him, upon an indictment

$\tau \hat{\omega} \nu \pi \rho \omega^{\prime} \tau \omega \nu \alpha \dot{\alpha} \nu \delta \hat{\omega} \nu$

by the principal men

$\pi \alpha \rho^{\prime} \dot{\eta} \mu \hat{\imath} \nu$

among us

48 Levenson and Martin, 'Critical Texts,' pp. 25-26 and 78; Whealey, Josephus on Jesus, pp. 2930 , and, on the Syriac equivalent, pp. 38-40, 185-192.

49 Paget, 'Some Observations', p. 247-8.

50 Numerous commentators have suggested 'called the Christ' was in the original TF; see Paget, 'Some Observations', p. 247 n. 274. 


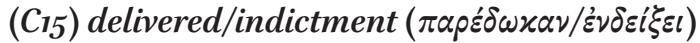

There are no Antiquities examples where a source's 'delivered' (Emmaus $\pi \alpha p \varepsilon \delta \delta \omega x \alpha \nu)$ is replaced by 'indicted' ( $\mathrm{TF} \dot{\varepsilon} \nu \delta \varepsilon \dot{\xi} \xi \varepsilon l)$. There is a passage that treats the verbs as near-synonyms: at War 7.47, a magistrate's son in Antioch has 'denounced' ( ( $\pi \alpha p \varepsilon \delta i \delta 0 v)$ some foreign Jews in a plot to burn the city. Josephus elsewhere uses $\dot{\varepsilon} v \delta \varepsilon \dot{\xi} \xi \varepsilon l$ for an accusation in fifteen instances.

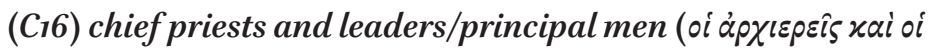

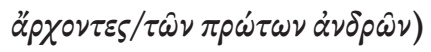

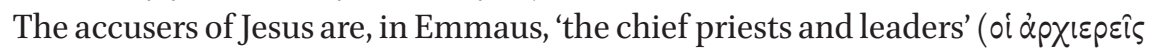

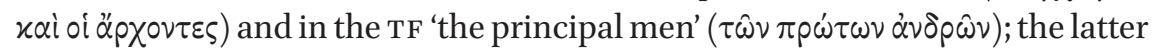
is one of Josephus's stock expressions for members of the ruling class. ${ }^{51}$ There are 14 examples of 'principal men' in the Antiquities, but only two are in pas-

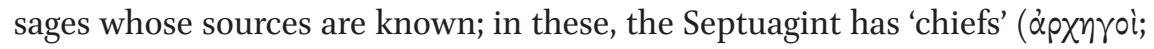
Num. 16.2/Ant. 4.21 and Num. 25.4/Ant. 4.140). More frequently Josephus uses 'the principal ones' (oi $\pi \rho \omega \hat{\tau} \tau \circ)$. In 1 Esdr. 8.66, 'leaders, priests and Levites [oi

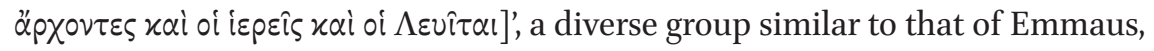

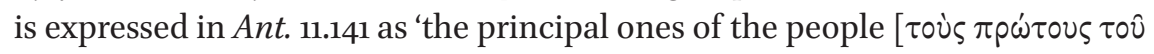

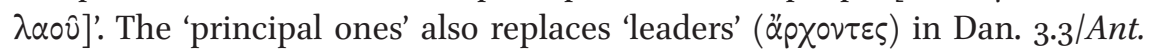
10.213 and War 2.237/Ant. 20.123.

\section{(C17) our/among us ( $\left.\dot{\eta} \mu \hat{\omega} \nu / \pi \alpha \rho^{\prime} \dot{\eta} \mu \hat{\imath} \nu\right)$}

The Emmaus narratives refer to 'our [ $\dot{\eta} \mu \hat{\omega} \nu]$ leaders'; in the TF equivalent, 'the principal men among us' ( $\pi \alpha \rho^{\prime}$ ' $\left.\dot{\eta} \hat{i} \mathrm{v}\right)$, the first person is an aberration, for, in historical narrative, Josephus takes care to write in the third person. For example, compare the more typical Ant. 14.165, where the accusers of Herod are the

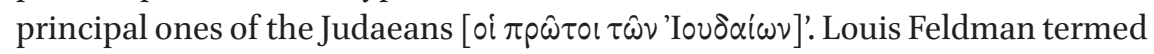
the TF's uncharacteristic use of the first person a 'stylistic peculiarity' that raises suspicions of forgery. ${ }^{52}$ Josephus, as a rule, only employs the first person when he digresses from historical narrative to comment directly to the reader on current Judaean cultural realities-'our laws', 'our festivals', etc. ${ }^{53}$ The TF is not of this type.

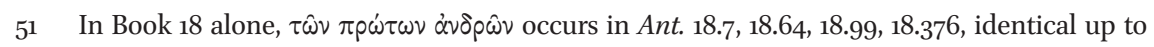
word order.

$5^{2}$ Feldman, Antiquities 18-19, p. 49, note b. The anomaly was first noted by Benedikt Niese: Whealey, Josephus on Jesus, p. 171. It has been taken as evidence of forgery by, e.g., Olson, 'Eusebius,' p. 312.

53 Whealey, contesting the idea that the first person in the TF is peculiar, presents examples in which Josephus uses the first person plural in describing his people; Josephus on Jesus, pp. 171-172, n. 7. But upon examination these are all authorial digressions of the type described. 
On the other hand, there are odd points where Josephus relates reported speech in the third person, and suddenly shifts to the first person; the lack of quotation marks makes it uncertain if these are intentional or mistakes. ${ }^{54}$ The most apt example is Ant. 11.143, where the third person is used consistently except at one point: 'he was ashamed because of the people, who had put out of their minds all the things that had befallen our fathers [ $\pi \alpha \tau p \alpha \dot{\sigma} \sigma \nu \dot{\eta} \mu \hat{\omega} \nu]$ because of their impiety.' One would have expected 'their fathers', as, for example, Ant. 8.127. The explanation is evidently in the source, 1 Esdr. 8.70-8.74. In this speech, Ezra confesses that 'ever since the time of our fathers $[\pi \alpha \tau \varepsilon$ ' $\rho \omega \nu$ $\eta \mu \omega \dot{\omega} v]$ we have been and are in great sin.' It appears evident that with 'our fathers' Josephus was careless while converting direct to indirect speech. But it was a thoughtful error- the inflection was changed to match the context.

In the same way, the first person in the Emmaus speech can have been transmitted into the TF. This also required a thoughtful adaptation, from 'our' $(\dot{\eta} \mu \hat{\omega} \nu)$ to 'among us' ( $\pi \alpha \rho$ ' $\dot{\eta} \mu \hat{i})$ ). Possibly the expression was so natural to him that he did not notice that in this instance it was out of context.

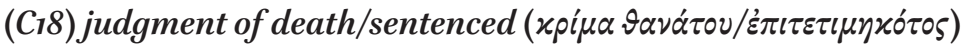

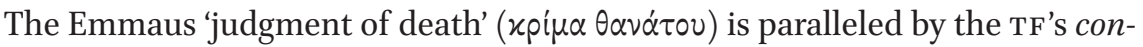

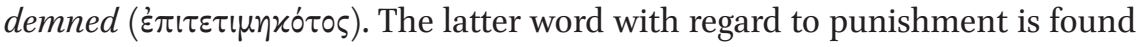
only twice where sources are known (but fourteen times in all, six in Book 18) and neither of these revise a source 'judgment of death'.55 Oddly, the combination 'condemn death [for oneself]' ( $\theta \dot{\alpha} v \alpha \tau \sigma \nu$ ह่ $\pi \imath \tau \mu \hat{\alpha} \nu)$ occurs in the next story after the TF (Ant. 18.68), the only Antiquities instance of this association.

Unlike Emmaus, the TF names Pilate and correctly distinguishes his role from that of the principal men.
Lk. 24.20
Ant. 18.64

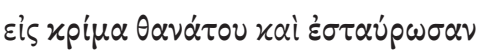

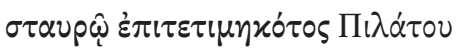

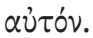

to a judgment of death and crucified to a cross condemned by Pilate, him

54 Begg, Early Divided Monarchy, pp. 123-124, n. 772.

55 Ex. 22.2/Ant. 4.272, a penalty owed; Josh. 22.16/Ant. 5.105, a verbal reprimand. 


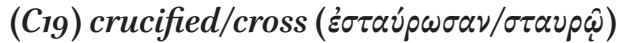

Emmaus uses the verb 'crucified', the TF the cognate noun 'cross'. Josephus employs 'cross' and 'crucified' over forty times, sixteen where sources are known, almost always as a rendering of 'tree' and 'hanged', and retaining the part of speech as noun or verb. There is only one instance of 'crucify' in the Septuagint, Esther 7.10, 'Let him be crucified thereon' (LXX $\sigma \tau \alpha \nu \rho \omega \theta \eta \dot{\eta} \tau \omega$, MT $t^{\prime}(u h u)$; this is revised at Ant. 11.267, 'ordered him at once to be hanged on that

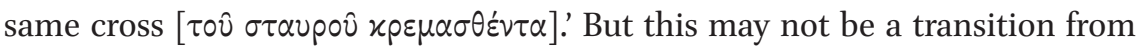
verb to noun, as it might reflect the prior sentence's 'tree' ( LXX $\xi \dot{\lambda} \lambda \circ v, \mathrm{MT}$ ets).

\section{$\left(C_{20}\right)$ we were hoping that he/those first loving him ( $\dot{\eta} \mu \varepsilon i \zeta \delta \dot{\varepsilon}$

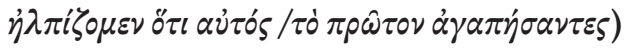

A notable content correspondence is that both texts, after relating the crucifixion, reference the previous high regard his followers had developed for Jesus. But in terms of vocabulary substitution, forms of the Emmaus verb 'hoping' ( $\lambda \lambda \pi i \zeta o \mu \varepsilon v)$ occur only nine times in Josephus's sources, none of them in a comparable context, so there is no direct evidence he would make this rephrasing. In some indirect evidence he would associate these words, the exact TF form of 'loving' $\alpha \gamma \alpha \pi \eta \dot{\eta} \sigma \alpha \nu \tau \varepsilon \varsigma$ appears only twice elsewhere in Josephus, and in one of these, Life 24, the people have the attribute of hope: 'those loving war' (oi rov

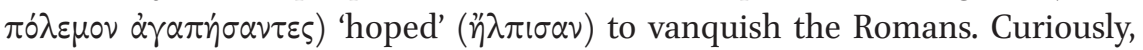
the 'hope' here is the same as in Emmaus, national liberation. Elsewhere, because John of Gischala would 'hope for' ( $\left.\dot{\varepsilon} \lambda \pi^{i} \sigma \alpha l\right)$ great things he 'loved' $(\dot{\alpha} \gamma \alpha \pi \hat{\alpha} \nu)$ war (War 4.85).

\section{(Omission) the one about to redeem Israel}

The TF does not have the Emmaus narrators' hope 'that he is the one about to

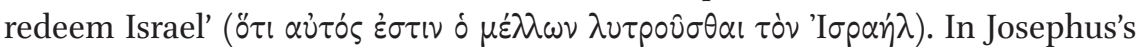
Lk. 24.21
Ant. 18.64

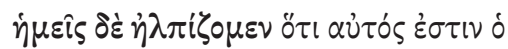

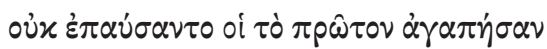

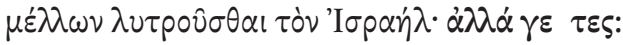

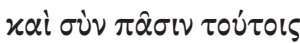

But we were hoping that he is the did not stop the first of those loving. one about to redeem Israel. And with all these things 
sources, the verse that is the most similar to that of Emmaus is 1 Macc. 4.11; in fact, Luke seems to be referencing it here. In that verse, Judah Maccabee speaks to his troops at Emmaus - in Church tradition, the same site as Jesus's appearance - and prays that heaven will grant them victory against Syria, 'and all the

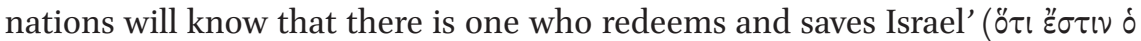

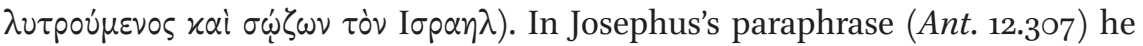
omits this line of Judah's speech. As plain meaning is a desire for national liberation, the omission is in keeping with his tendency to avoid prophecies against the ruling empire. ${ }^{56}$ By analogy, he would also omit the very similar Emmaus remark. Moreover, if Josephus had included the hope for liberation in the TF, he would have been unjustly depicting contemporary Christians as adherents to an anti-Roman ideology.

(C21) and with all these things \& some women among us*/did not

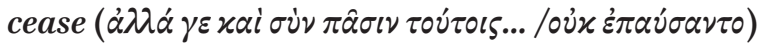

At the analogous location to the TF's 'did not cease' (ov่x ह่ $\pi \alpha \nu$ $\sigma \alpha \nu \tau 0)$, Emmaus depicts the followers' despair and then their encouragement by the women's story. There is an interesting parallel for this way of abbreviating continuing activity: a list of heretical actions by the northern kingdom (2 Kgs 7.7-23) is

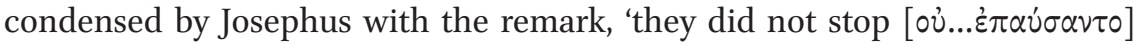
their lawlessness' (Ant. 9.266). ${ }^{57}$ The avoidance of the women's story is consistent with Josephus's tendency to omit certain material he finds problematic, such as angels. ${ }^{58}$

Lk. 24.21-25

Ant. 18.64

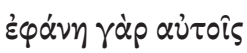

For he appeared to them

$\tau p i ́ \tau \nu \nu \tau \alpha \tau^{\tau} \eta \nu \dot{\eta} \mu \varepsilon \dot{\varepsilon} \rho \nu \alpha ̋ \gamma \varepsilon เ$

$\tau \rho i \tau \eta \nu$ है $\chi \omega \nu \dot{\eta} \mu \varepsilon \dot{p} \alpha \nu$

brings this third day

a third day having

56 Feldman, Interpretation, pp. 39, 649-652.

57 This is repeated a little later as $\mu \eta \dot{~} \pi \alpha v \sigma \alpha \mu \varepsilon \dot{v} o ı$ at Ant. 9.281. Begg, Later Monarchy, pp. 34950, 372-373.

$5^{8}$ Feldman, Interpretation: Josephus's suspicion of women's speech, p. 191; omission of angels, pp. 212-213; and sensitivity to the accusation of credulity of Jews, p. 209. 

Lk. 24.21-25
Ant. 18.64

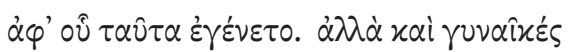

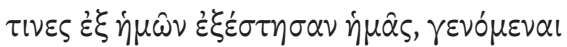

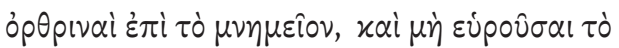

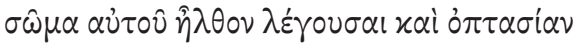

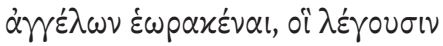

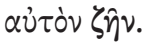
$\pi \dot{\alpha} \lambda \iota \nu \zeta \hat{\omega} \nu$

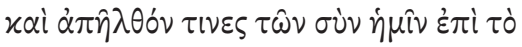

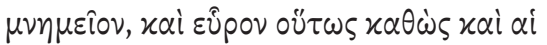

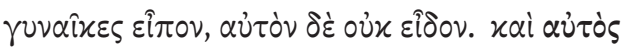

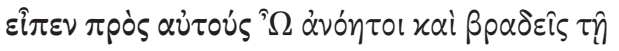

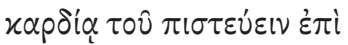

today since these things occurred; and some women astounded us who had been early at the tomb, and not finding the body came saying they had seen a vision of angels who said

he lived.

living again

And some of those went with us to the tomb and found as the women said; but saw him not. And he said to them, "Oh, senseless ones and slow of heart to believe in

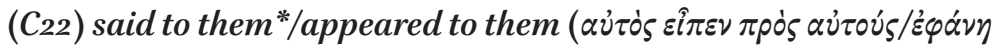

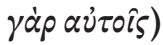

The dramatic turn in Emmaus is, 'And he said to them'; in the TF, 'he appeared [' $\left.\varphi_{\alpha} \alpha \nu\right]$ to them'. The difference reflects the TF's absence of the dialog framework. Surprisingly, one finds this association of terms in other paraphrases: there are a number of biblical verses where God or an angel speaks and Josephus, in his paraphrase, inserts a word for an appearance (with the TF's 
root $\varphi \alpha i v \omega) .{ }^{59}$ An example is 2 Sam. 7.4, "That night the word of the Lord came to Nathan saying'; paraphrased at Ant. 7.92 as, 'But that night God appeared

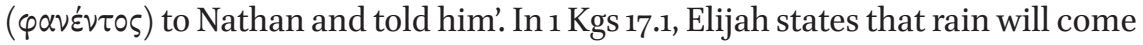

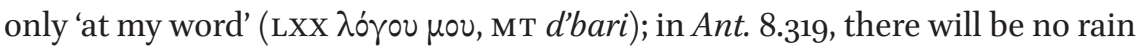

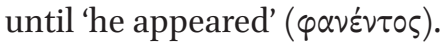

In contrast to Emmaus's vivid encounter, the TF gives a tepid report.Josephus does have a tendency to lessen miracles. ${ }^{60}$ And the account is consistent with Greek historiographical practice; as Lucian would later advise, 'an extraordinary tale should be narrated simply for the audience to make of it what they will, so that the author does not take a risk by inclining to either side.'61

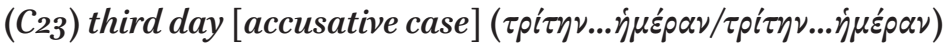

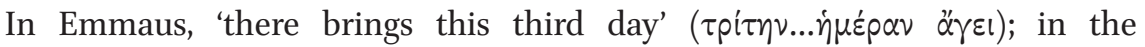

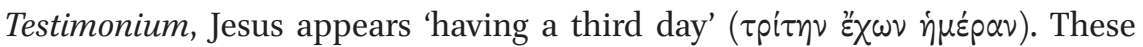
verb phrases with the accusative 'third day' are distinct from the traditional

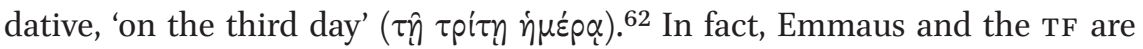
the only texts with the resurrection 'third day' as the object of a verb in all of ancient literature.

Support for an Emmaus influence is that Josephus does have a strong tendency to duplicate the grammatical case of his source in the matter of day periods. He does this in all eight instances where he takes 'day(s)' from 1 Esdras; for example, at Ant. 11.148, the dative 'in two or three days' is an exact copy of 1 Esdr. 9.4. ${ }^{63}$ In the paraphrase of Aristeas, there are three instances where he duplicates the inflection versus two where he changes it. ${ }^{64}$ In revising 1 Maccabees, there are nine duplications versus one change. ${ }^{65}$ Thus, for these known Greek sources, $87 \%$ of the time Josephus does copy the day period inflection.

59 Begg cites Gen. 22.1/1.223, 2 Sam. 7.4/7.92, 1 Kgs 13.20/8.240, 1 Kgs 14.5/8.268, 1 Kgs 18.12/8.333, 2 Kgs 1.3/9.20, Jer. 42.7/10.177, and 1 Sam. 8.7/6.38; Early Divided Monarchy, pp. 53-54 n. 300, and Later Monarchy, p. 32, n. 16.

6o Feldman, Interpretation, pp. 209-214; Studies, pp. 568-570.

61 Lucian, How to Write History 6o.

62 The peculiarity of the TF expression has been taken as evidence of Josephan authorship; Feldman, Antiquities 18-19, p. 49, note b. However, Meier suggests a Christian interpolator was influenced by Emmaus; A Marginal Jew, p. 83, n. 42.

631 Esdr. 4.63/Ant. 11.66, 7.14/11.110, 8.41/11.134, 9.11/11.150 (these are in acc. pl.); 9.5/11.148 (dative pl.); 6.29/11.119 (acc. sing.); 9.41/11.155 (gen. sing.).

64 The grammar is copied in Aristeas 27/Ant. 12.33 (dative pl.), 180/12.92 (acc. sing.), and 307/12.107 (dative pl.); changed in 301/12.103 and 314/12.112; 24/12.31 does both.

65 Matching: 1 Macc. 4.54/Ant. 2.320-1, 7.48/12.412 (acc. sing.); 4.56/12.323, 4.59/12.325, 9.20/12.432, 9.64/13.27 (acc. pl.); 5.24/12.336 (gen. pl.); 10.30/13.50-51 (gen. sing.); 12.11/13.168 (dative pl.). The changed case is $5.50 / 12.347$. 


\section{(C24) brings/having ( $\left.{ }^{\prime \prime} \gamma \varepsilon l /{ }^{\prime \prime} \chi \omega \nu\right)$}

There are no Antiquities paraphrases replacing 'brings' (a' $\gamma \varepsilon \iota)$ with 'having' $\left({ }^{\prime} \chi \omega \nu\right)$. But Josephus is known to use either verb with time. There are five cases of 'have' ( $\left.\varepsilon^{\prime} \chi \omega\right)$ with 'day(s)' as its object; in each the source has a different verb. The most similar to the TF is Ant. 7.1, 'David passing two days in Sikella' (סío

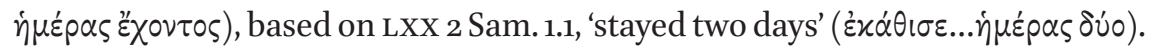
The others are Ant. 2.72, 3.29o, 5.327, and 9.223, all marking time passing. There are eight instances of $\alpha \gamma \omega \omega$ with day(s), all of them in the sense of time spent observing festivals; for example, Ant. 2.317, 3.245, 8.123. The usage suggests he would consider 'have' more appropriate than 'brings' in the TF context.

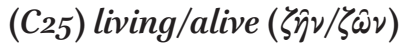

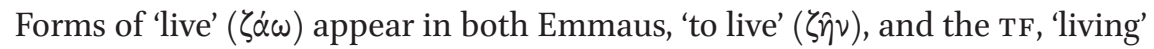
( $\zeta \omega v)$, in similar locations (between 'third day' and 'prophets') and in reference to Jesus's resurrection. But their contexts differ significantly, as the TF does not have the story of the women. In the definite Greek sources, Josephus copies $\zeta \hat{\eta} \nu$ from 1 Macc. 2.13 into Ant. 12.267, and adapts the cognate 'made alive' ( $\zeta \omega 0 \pi 0100 \hat{v \tau \alpha l)}$ of Aristeas 16 to $\zeta \hat{\eta} \nu$ in Ant.12.22. A parallel to the TF, if Josephus

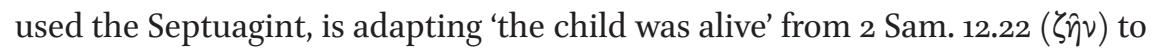

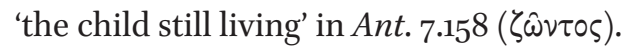

The TF 'again' ( $\pi \dot{\alpha} \lambda \imath v)$, which modifies 'living' and implies a physical resurrection, has no simple vocabulary equivalent in Emmaus.

Lk. 24.25-27

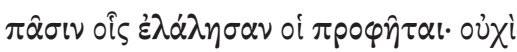
$\tau \alpha \hat{\tau} \tau \alpha$ हैठฮा

all that the prophets have spoken. Were not these things necessary

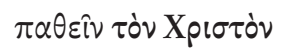

to suffer the Christ

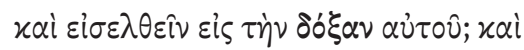

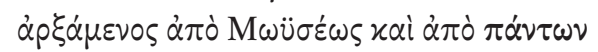

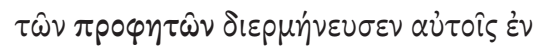

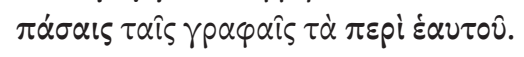

Ant. 18.64

$\tau \hat{\omega} \nu \theta \varepsilon i \omega \nu \pi \rho \circ \varphi \eta \tau \omega \hat{\nu} \tau \tau \alpha \hat{v} \tau \dot{\alpha}$ the divine prophets these things (displaced; see $\mathrm{C} 14)$

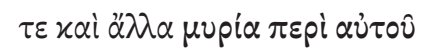

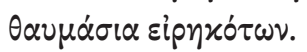


and to enter into his glory? And from Moses and all the prophets he interpreted to them in all the Scriptures the things about himself. and countless other wonders about him having foretold.

\section{(C26) prophets ( $\pi \rho \circ \varphi \eta \hat{\tau} \tau \iota$ \& $\pi \rho \circ \varphi \eta \tau \hat{\omega} \nu / \pi \rho \circ \varphi \eta \tau \hat{\nu} \nu)$}

The word 'prophets' occurs twice in the Emmaus narrative and once in the Testimonium. In both texts, what the prophets foretold encourages the followers after the crucifixion. Unsurprisingly, Josephus frequently adopts 'prophets' where it occurs in his biblical source; its adoption here, in a scriptural context, would not present the problem seen with 'prophet man' $\left(\mathrm{C}_{5}\right)$. As a point of style, TF 'divine prophets' ( $\tau \hat{\omega} v \theta \varepsilon i \omega v \pi \rho \circ \circ \eta \tau \hat{\omega} v)$ recalls the characterization in

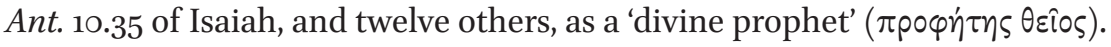

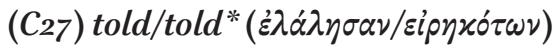

In Emmaus, the prophets 'have spoken' ( $\dot{\varepsilon} \lambda \dot{\alpha} \lambda \eta \sigma \alpha \nu$ ), in the TF (in the follow-

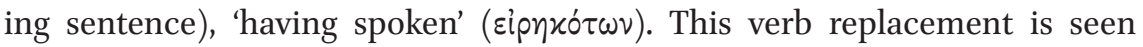
throughout the Antiquities: where the Septuagint has $\lambda \alpha \lambda \varepsilon \dot{\varepsilon} \omega$, Josephus will use ह̇ $\hat{\omega} \omega$. For example, in 2 Chron. 18.12, what the prophets 'had spoken' (LXX $\dot{\varepsilon} \lambda \alpha^{\prime} \lambda \eta \sigma \alpha v$; no equivalent verb in the Hebrew) becomes in Ant. 8.404 'had fore-

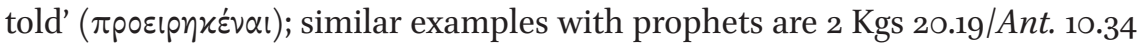
and 1 Kgs 17.16/Ant. 8.323. ${ }^{66}$

The TF verb is the last word in the sentence, while in Emmaus the equivalent falls earlier. Pelletier has demonstrated that Josephus does have a strong tendency to transfer the verb in his source to the end of a sentence. ${ }^{67}$

\section{(C28) these things ( $\tau \alpha \hat{\tau} \tau \alpha / \tau \alpha \hat{\tau} \tau \alpha$ )}

Emmaus's prophecies have two stages: 'these things' ( $\tau \alpha \hat{\tau} \tau \alpha)$ that Jesus has suffered, and unspecified things regarding his 'glory'. In the $\mathrm{TF}$, there is a similar division: the prophets foretold 'these things' ( $\tau \alpha \hat{\tau} \tau \alpha)$ and many other unnamed 'wonders' about him.

66 It is likely Josephus was working directly from the Septuagint (OG) in these verses: Begg, Early Divided Monarchy, pp. 270-276; Late Monarchy (with less confidence), pp. 625-626.

67 Pelletier, Lettre d'Aristée, pp. 222-223. 
The adoption of $\tau \alpha \hat{\tau} \tau \alpha$ from a source is indeed seen on occasion in Josephus's paraphrases: for example, Aristeas 28/Ant. 12.34, 'When these things had been done', and 1 Esdr. 9.15/Ant. 11.151. Consider, then, Macc. 11.42: Demetrius said, " Not only will I do these things [ $\tau \alpha \hat{\tau} \tau \alpha]$ to you and to your nation, but also I will glorify [ $\alpha \lambda \lambda \dot{\alpha} \delta \delta \xi \eta \eta \emptyset 0 \xi \dot{\alpha} \sigma \omega]$ you and your nation greatly."' Similar to Emmaus, this has two parts, 'these things' and 'glory'. It is paraphrased at Ant. 13.134: 'Demetrius promised not only to grant him these things [ $\tau \alpha \hat{\tau} \tau \alpha]$, but also to

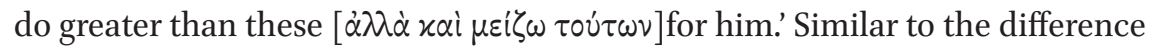
between the TF and Emmaus, this paraphrase duplicates 'these things' and adds on, using $\dot{\alpha} \lambda \dot{\alpha} x \alpha i$, more spectacular things.

\section{(C29) all/countless ( $\pi \hat{\alpha} \sigma \iota \nu \& \pi \dot{\nu} \tau \tau \omega \nu \& \pi \dot{\sigma} \sigma \alpha \iota s / \mu \nu p i ́ \alpha)$}

Emmaus's 'all' versus the TF 'countless' has a parallel: 2 Chr 7.22 'all this evil'

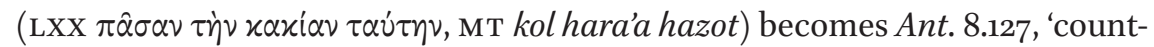

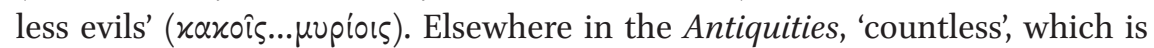
used 110 times, renders a source's unspecified large numbers. Examples are Josh. 11.4/Ant. 5.64, Num. 23.10/Ant. 4.14 and 2 Chron. 6.16/Ant. 8.113. There is an interesting stylistic parallel in the introduction to the Antiquities: 'Countless $[\mu v p i \alpha]$ are the things revealed through the sacred scriptures' (Ant. 1.13).

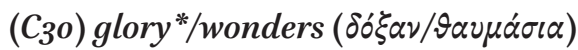

There are prophecies of 'glory' (Emmaus) or of 'wonders' (TF). There is no known paraphrase where Josephus replaces 'glory' $(\delta \delta \hat{\delta} \xi \alpha)$ by 'wonders'

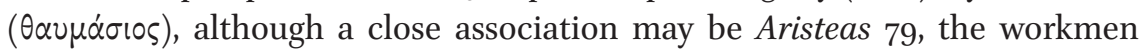
'designed all to be worthy of the glory [ $\left.\delta \delta^{\prime} \xi \eta \zeta\right]$ of the king', revised to Ant 12.83, the workmen were 'wonderful $[\theta \alpha \nu \mu \alpha \sigma i \omega \nu]$ in such fine work. For worldly glory, the words appear together at Ant. 6.80: Saul has a 'marvelous renown' ( $(\alpha \nu \mu \alpha \sigma \tau \hat{\varsigma} \varsigma . . . \delta o ́ \xi \eta \varsigma)$ for valor. Josephus omits 'glory' where his biblical source uses it in a divine sense, as in the 'glory of the Lord'.

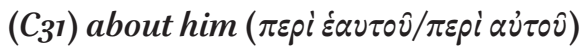

'About himself' ( $\pi \varepsilon p \grave{i} \varepsilon \alpha \nu \tau \odot \hat{)})$, the last words of the Emmaus excerpt, has a near

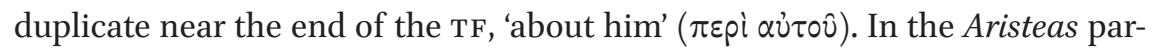
aphrase, there are six cases that parallel the source's $\pi \varepsilon p i$ with a sometimes

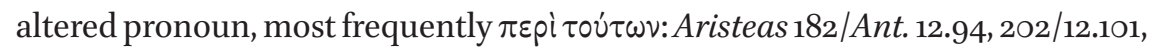
20/12.26, 24/12.30, 37/12.47, 40/12.50 There are two cases from 1 Esdras: 1 Esdr. 6.6/Ant. 11.95 and 6.21/11.98. With the Septuagint, there are, e.g., Dan. 10.14/Ant. 10.239 and 1 Sam. 19.3/Ant. 6.207. 
Ant. 18.64

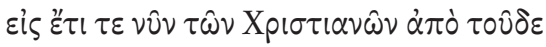

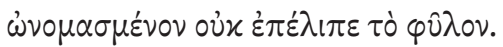

And still to now the group of

Christians, so named after this one, has not disappeared.

\section{(Addition) and Still to Now the Tribe of the Christians, so Named after this one, has Not Disappeared}

The last sentence of the Testimonium has no parallel in the Emmaus narrative. The addition is consistent with Josephus's frequent practice of ending his paraphrases with a closing statement of his own creation. ${ }^{68}$ These notices often bring the narrative to the present with a transition such as 'still to now' and, similar to this line's interest in the term Christians, can stress the origin of names. For example, at the end of the paraphrase of Gen. 21, Ant. 1.212 adds: 'It

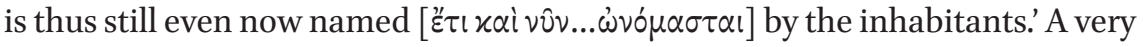
similar notice is added in Ant. 3.299 to the end of Num. 11, and in Ant. 8.154 to the end of 2 Chron. 8; and Ant. 11.173 adds to the end of Neh. 3 that the Judaeans have been called by that name, after the tribe of Judah, 'since the time' of the return from Babylon.

Some questions have been raised about the vocabulary of the sentence, but I think these have been well answered, especially by Whealey. The combination

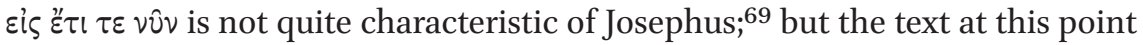
is uncertain, and the earliest codices are representative of his style. ${ }^{70}$ Also, it has been questioned whether Josephus would refer to Christians as a $\varphi \hat{\imath} \mathrm{v}_{\mathrm{v}}$ (often rendered as tribe). ${ }^{71}$ But it now seems clear $\varphi \hat{v} \lambda$ ov is the translation of the common Latin term for the Christians circa Josephus's time, a genus. ${ }^{72}$ In

68 See, for example, the comments on Josephus's 'closing notices' listed in the index of Begg, Later Monarchy, p. 702.

69 Feldman, 'Authenticity,' p. 26; Olson, 'Eusebius,' p. 312.

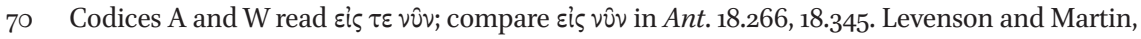
'Critical Texts,' p. 22 n. 135; Whealey, 'Eusebius', pp. 100-105.

71 Olson, 'Eusebius,' p. 312.

72 The Christian genus is evidenced in Suetonius, Nero 16.2, and in the quote of Trajan in Tertullian, Apology 2.7. The Greek translation in Hist. eccl. 3.33.2 of the latter renders genus as $\varphi \hat{v} \lambda \circ \mathrm{v}$, and conversely the early Latin versions of the TF translate $\varphi \hat{v} \lambda$ v as genus; Levenson and Martin, 'Critical Texts,' p. 23. Detailed in Whealey, 'Eusebius,' pp. 97-100; Josephus on Jesus, pp. 180 and 199 n. 36 . 
short, the style and substance of this sentence are typical of a Josephus closing statement.

\section{Summary}

Of the 31 numbered correspondences, there are 12 shared word roots in the proper context. These are: $\left(\mathrm{C}_{1}\right)$ happens. $\left(\mathrm{C}_{3}\right)$ Jesus. $\left(\mathrm{C}_{4}\right)$ man. $\left(\mathrm{C}_{7}\right)$ deeds. (C14) the Christ. [definite article only] (C17) our/among us. (C19) crucified/ cross. $\left(\mathrm{C}_{23}\right)$ third day [accusative case]. $\left(\mathrm{C}_{25}\right)$ alive. $\left(\mathrm{C}_{2} 6\right)$ prophets. $\left(\mathrm{C}_{2} 8\right)$ these things. $\left(\mathrm{C}_{31}\right)$ about him.

There are 9 vocabulary pairs with paraphrase support for substitution. These are: $\left(\mathrm{C}_{2}\right)$ in these days/about this time. (C8) deed before the people/surprising. (C9) powerful in word/teacher. (C11) all/many \& many. (C16) chief priests and leaders/principal men. (C22) said to them/appeared to them. (C27) told/told. (C29) all/countless. To this list I add did not cease (C21), as a summarization of a series of continued actions.

There are least 8 pairs with indirect support through association of usage: (C5) prophet/wise. (C6) powerful in deed/doer [the cognate verb, not the noun]. (C10) word before God/truth. (C12) people/people \& Judaeans \& Greeks. (C15) delivered/indictment. $\left(\mathrm{C}_{20}\right)$ we were hoping that he/those first loving [him]. (C24) brings/having. ( $\left.\mathrm{C}_{3} \mathrm{O}\right)$ glory/wonders.

The remaining 2 pairs have no explicit parallels for vocabulary replacement: (C18) judgment of death/sentenced. ( $\left.\mathrm{C}_{13}\right)$ we were hoping/won over.

The content modifications have been seen to be consistent with Josephus's characteristic alterations. The main rearrangement is $\left(\mathrm{C}_{14}\right)$ ho Christos. The significant omissions/condensations are the dialog framework, the women at the tomb, and 'the one to redeem Israel'. The major additions/enhancements are Pilate (C18), Greeks (C12), received truth with pleasure (C10), if one should call him a man, and the closing statement.

\section{Alternative Explanations}

The most salient alternative to a paraphrase explanation is that the correspondences are a series of coincidences. This raises the question of probability. Are thirty-one ordered content parallels a significant number to find in texts of this size? How many Antiquities paraphrase parallels could one expect to find? The most straightforward way to answer these questions is to compare other descriptions of Jesus of a similar length to Emmaus, in order to determine if they, too, can be judged consistent with Josephus's paraphrase style. 
The full results are too extensive for this article; what follows is a very brief summary. First, compare the Nicene Creed of $381 \mathrm{CE}$ (174 words). For the simplest evidence, the word roots shared with the TF, there are 6:Jesus, Christ (but without the article), crucified, Pilate, on the third day (but dative), and prophets. There are perhaps a total of 9 content correspondences, not necessarily in order, far less than Emmaus, and many content differences.

A richer set of comparisons is found in the speeches of Acts. The excerpts summarized here are Acts 2 (2.22-33), Acts 3 (3.13-24), Acts 5 (5.30-32), Acts 10 (10.36-43), and Acts 13 (13.23-41). These average about 165 words, not counting embedded biblical quotations.

The Acts speeches have respectively, 4, 4, 1, 7 and 4 word root matches with the Testimonium, an average of 4 . In content correspondences, but disregarding position, I count 13, 13, 4, 17, and 14 potential matches with the TF (granting that others might count differently), for an average of 12.2. In both of these measures, Emmaus (12 roots, 31 content) far exceeds their average and is about twice their maximum (Acts 10 in both cases, which has many similarities to Emmaus).

In the category of substitutions with paraphrase support, the speeches average 2.2, versus 7 for Emmaus. Of these, the only substitution that does not also occur in Emmaus is hanged from a tree (Acts 5 and 10), a Septuagintism that Josephus typically converts to cross/crucify. Expressions without paraphrase support are rejected, proclaimed, and raised, among others. These examples show that the Antiquities is not so large that one can find evidence that any given expression can be paraphrased into a TF term. Most of all, synoptic comparisons of the speeches with the TF are poor compared to the foregoing Emmaus-TF exhibits.

Justin Martyr and Ignatius of Antioch also have several short descriptions of Jesus. ${ }^{73}$ Suffice it to say that the results of these comparisons fall between those of the Acts speeches and the Nicene Creed.

One can now attempt to answer the probability question. For the given measures, the Emmaus text is at least 3.7 standard deviations above the mean of the other texts. By the simplest estimate (a normal distribution), the probability that the Emmaus-TF correspondences are due to chance is about one in ten thousand. I do not want to put too much weight on statistical arguments with this type of sample set. But this estimate does give some quantitative perspective to the synoptic evaluations.

73 Justin, First Apology 6, 13, 21, 31, 42, 46; Dial 63.1, 85, 126, 132. Ignatius, Trall. 9, Ephes. 18, Smyrn. 1. 
If coincidence is then excluded, an alternative explanation is that a sophisticated forger deliberately rewrote Luke $24.18-27$ using Josephus's vocabulary. But it is counterproductive for a forger to closely follow the template of one writer in order to create an imitation of another-it would debase the feeling of authenticity. And there are many changes to Emmaus that are natural for Josephus to make for the TF that are difficult to understand coming from a Christian writer: the treatment of Septuagintisms, the intermittent adoption of words such as the non-creedal form of the 'third day', the lowered tone, the mild expansion of 'mighty in deed and word' without added specifics such as healing, the addition of a large Greek following in contradiction to the gospel, the omission of the empty tomb, and so on. It seems one gains only problems and no advantages with this alternative.

\section{Concluding Remarks}

This study has shown that there is a path Josephus can have taken to revise the Emmaus narrative into the Testimonium by employing his known methods of revision. How confident can one be in this model? It must be acknowledged that the evidence is not of uniform strength. Where Emmaus is vague, e.g. 'mighty in word and deed', when the TF is more specific, the argument of parallel content is necessarily weaker; one must postulate Josephus's use of a second source. Other additions and omissions marked out notable differences between the texts, and these were argued to be reasonable based on parallels in Josephus's writing. If the plausibility of these modifications is granted, then one can say that the sequence of the Emmaus template is followed quite closely.

The majority of the vocabulary modifications have good parallels among Josephus's known paraphrases, but others rely for support on additional examples of Josephus's usage, as shown in the Summary given above. The evidence is not of equal quality, as the number of parallels that can be found is subject to the vagaries of the resemblances between Emmaus and Josephus's other sources. The same variations of evidence could be expected in examining any of Josephus's paraphrases; an analysis of this point would be helpful. And some substitutions are more distinctive of Josephus than others. Even given occasional weaknesses, the cumulative evidence of substitutions strikes one as surprising. As observed above, comparison with other ancient descriptions of Jesus confirms the significance of this amount of evidence.

In the Introduction I outlined the principal advantages of the paraphrase model over current theories of the TF: that it is simple, powerful, and free of 
assumptions about Josephus's attitude toward Christianity. A fuller treatment of the literature on the $\mathrm{TF}$, including various suggestions of editing, in light of the model would be useful.

I will conclude with some implications of the model. The study shows Josephus closely following a Christian source and treating it with a degree of courtesy and guarded respect. He modified Emmaus to flatter the followers as truth seekers, suggesting he had acquaintances among the (Jewish) Christian community in Rome.

In order to write about the Christians without committing errors or offense, he would have required a trustworthy source. An ideal step would have been to obtain a document from the historians in the Christian community in Rome. Both Josephus (Apion 1.53-54) and Luke (Lk. 1.1) declared their Thucydidean ambition to employ first-hand accounts, so a valued document from Luke's circle should have been a perfect candidate.

Josephus would know if the Emmaus account could be trusted. Although he was born in 37 or $38 \mathrm{CE}$, and so was not an eyewitness to Jesus, he grew up in Jerusalem acquainted with the same generation of 'principal men' that he mentions in the TF (Life 9), among whom he counted his father, Matthiaswho would have been, for example, twenty-seven years old in 33 CE (Life 5-7). Josephus became the wartime subordinate and the friend of a friend of Ananus II, the high priest that brought about the death of 'the brother of Jesus called Christos, James his name' (Ant. 20.200). ${ }^{74}$ If Josephus had never heard from his own father, Ananus II's circle, or other principal men about an extraordinary controversy surrounding Jesus, he could not have accepted the Emmaus source as valid for use in the Antiquities.

Considering his normal rate of composition, the paraphrase probably took him a single day. ${ }^{75}$ As a consequence of his work, Josephus validates that the elements of a key gospel passage was in existence in the gOS CE and that it acceptably transmitted knowledge and beliefs about Jesus that had originated in the time of Pilate, the time of Josephus's parents.

74 War 2.563-2.568; Life 193-196, 204.

75 Composition rate: Feldman, Interpretation, p. 55-56. 